\title{
Exposure, probable PTSD and lower respiratory illness among World Trade Center rescue, recovery and clean-up workers
}

\author{
B. J. Luft' ${ }^{1}$, C. Schechter ${ }^{2}$, R. Kotov ${ }^{3}$, J. Broihier ${ }^{1}$, D. Reissman ${ }^{4}$, K. Guerrera ${ }^{1}$, I. Udasin ${ }^{5}$, J. Moline ${ }^{6}$, \\ D. Harrison ${ }^{7}$, G. Friedman-Jimenez ${ }^{7}$, R. H. Pietrzak ${ }^{8,9}$, S. M. Southwick ${ }^{8,9}$ and E. J. Bromet ${ }^{3 *}$ \\ ${ }^{1}$ Department of Medicine, Stony Brook University, Stony Brook, NY, USA \\ ${ }^{2}$ Department of Family and Social Medicine, Albert Einstein College of Medicine, New York, NY, USA \\ ${ }^{3}$ Department of Psychiatry, Stony Brook University, Stony Brook, NY, USA \\ ${ }^{4}$ Office of the Director, National Institute for Occupational Safety and Health, Washington, DC, USA \\ ${ }^{5}$ Environmental and Occupational Health Sciences Institute, University of Medicine and Dentistry of New Jersey, Piscataway, NJ, USA \\ ${ }^{6}$ Department of Population Health, Hofstra North Shore-Long Island Jewish School of Medicine, Great Neck, NY, USA \\ ${ }^{7}$ Departments of Medicine and Environmental Medicine, New York University School of Medicine and Bellevue Hospital Center, New York, \\ NY, USA \\ ${ }^{8}$ Department of Psychiatry, Yale University School of Medicine, National Center for Posttraumatic Stress Disorder, VA Connecticut Healthcare \\ System, West Haven, CT, USA \\ ${ }^{9}$ Department of Psychiatry, Mount Sinai School of Medicine, New York, NY, USA
}

Background. Thousands of rescue and recovery workers descended on the World Trade Center (WTC) in the wake of the terrorist attack of September 11, 2001 (9/11). Recent studies show that respiratory illness and post-traumatic stress disorder (PTSD) are the hallmark health problems, but relationships between them are poorly understood. The current study examined this link and evaluated contributions of WTC exposures.

Method. Participants were 8508 police and 12333 non-traditional responders examined at the WTC Medical Monitoring and Treatment Program (WTC-MMTP), a clinic network in the New York area established by the National Institute for Occupational Safety and Health (NIOSH). We used structural equation modeling (SEM) to explore patterns of association among exposures, other risk factors, probable WTC-related PTSD [based on the PTSD Checklist (PCL)], physician-assessed respiratory symptoms arising after 9/11 and present at examination, and abnormal pulmonary functioning defined by low forced vital capacity (FVC).

Results. Fewer police than non-traditional responders had probable PTSD (5.9\% v. $23.0 \%$ ) and respiratory symptoms $(22.5 \%$ v. $28.4 \%)$, whereas pulmonary function was similar. PTSD and respiratory symptoms were moderately correlated ( $r=0.28$ for police and 0.27 for non-traditional responders). Exposure was more strongly associated with respiratory symptoms than with PTSD or lung function. The SEM model that best fit the data in both groups suggested that PTSD statistically mediated the association of exposure with respiratory symptoms.

Conclusions. Although longitudinal data are needed to confirm the mediation hypothesis, the link between PTSD and respiratory symptoms is noteworthy and calls for further investigation. The findings also support the value of integrated medical and psychiatric treatment for disaster responders.

Received 3 August 2011; Revised 2 October 2011; Accepted 14 October 2011; First published online 18 November 2011

Key words : 9/11, disaster responders, exposure, mediate, post-traumatic stress disorder, respiratory conditions, risk factors, World Trade Center.

\section{Introduction}

The September 11, 2001 (9/11) terrorist attack on the World Trade Center (WTC) was an extraordinary

* Address for correspondence: E. Bromet, Ph.D., Distinguished Professor, Departments of Psychiatry and Preventive Medicine, Stony Brook University, Stony Brook, NY 11794, USA.

(Email: Evelyn.bromet@stonybrook.edu) environmental disaster with unprecedented physical hazards to rescue and recovery workers from the disintegrated structure and contents of the WTC buildings, the combustion of 90000 liters of jet fuel from the hijacked planes, and the smoldering debris fire under the 'pile' (Gavett, 2003; McGee et al. 2003; Landrigan et al. 2004; Lioy \& Georgopoulos, 2006). At the same time, responders were exposed to extreme trauma from the loss of colleagues and friends, witnessing

The online version of this article is published within an Open Access environment subject to the conditions of the Creative Commons Attribution-NonCommercial-ShareAlike licence <http://creativecommons.org/licenses/by-nc-sa/2.5/ $>$. The written permission of Cambridge University Press must be obtained for commercial re-use. 
death and destruction, handling dead bodies, body parts, fluids and personal effects, and inhaling the caustic odor of burning and decomposing bodies and debris.

As a consequence, respiratory ailments and posttraumatic stress disorder (PTSD) became the two persistent, signature health problems among WTC rescue, recovery and clean-up workers. Specifically, elevated rates of respiratory symptoms, asthma and abnormal lung function were reported from 3 months to 9 years later (Levin et al. 2002; Prezant et al. 2002; CDC, 2004; Herbstman et al. 2005; Tapp et al. 2005; Brackbill et al. 2006, 2009; Herbert et al. 2006; Wheeler et al. 2007; Aldrich et al. 2010; Niles et al. 2011; Wisnivesky et al. 2011). One year after the disaster, nearly half of the workers evaluated at the WTC Medical Monitoring and Treatment Program (WTC-MMTP) reported incident WTC-related upper (49.6\%) and lower (39.5\%) respiratory symptoms, and $31 \%$ of non-smokers had abnormal spirometry findings (CDC, 2004); by 9 years, the cumulative incidence of spirometric abnormalities was $41.8 \%$ (Wisnivesky et al. 2011). Being in the dust cloud with its airborne toxins and longer duration of time working at the site significantly elevated the risk of respiratory problems (e.g. Aldrich et al. 2010).

High rates of probable PTSD assessed with selfreport measures such as the PTSD Checklist (PCL) have also been reported for responder cohorts (Perrin et al. 2007; Bills et al. 2008; Farfel et al. 2008; Stellman et al. 2008; Brackbill et al. 2009; Berninger et al. 2010; Niles et al. 2011; Wisnivesky et al. 2011). For example, a study of firefighters found annual rates for the first 4 years after $9 / 11$ of about $10 \%$ per year (Berninger et al. 2010). Similarly, the rate for the WTC-MMTP cohort, assessed from 10 to 61 months after 9/11, was $11.1 \%$ (Stellman et al. 2008). Among responders in the WTC Health Registry, the rate of probable PTSD was three times higher in unaffiliated volunteers $(21.2 \%)$ than in police $(6.2 \%)$ (Perrin et al. 2007). Similar to respiratory symptoms, exposure to the dust cloud and longer duration of work were significant risk factors for PTSD (e.g. Brackbill et al. 2009).

Studies of combat veterans (Hoge et al. 2007), general population samples (Goodwin et al. 2003; Eaton, 2005; Scott et al. 2009; Spitzer et al. 2009; Von Korff et al. 2009) and primary care patients (Yellowlees \& Kalucy, 1990; Üstün \& Sartorius, 1995; Weisberg et al. 2002) have consistently found a strong relationship between physical and mental health in general, and between respiratory symptoms and PTSD specifically (e.g. Engel, 2004; Spitzer et al. 2009), including in two recent studies of WTC responders (Niles et al. 2011; Wisnivesky et al. 2011). There are at least three explanations for this link. First, the association between respiratory symptoms and PTSD symptoms may be coincidental, being the result of the same exposures contributing to both conditions. Second, PTSD is associated with immunologic dysregulation (McEwen \& Stellar, 1993; Chrousos, 1995; Delahanty et al. 1997; Ironson et al. 1997; Boscarino \& Chang, 1999; Schnurr \& Jankowski, 1999), which may increase pulmonary inflammation and autonomic dysregulation resulting in respiratory abnormalities (Blechert et al. 2007). Furthermore, the cognitive and attentional processes associated with PTSD may increase perception and reporting of respiratory symptoms (Dales et al. 1989; Yellowlees \& Kalucy, 1990; Üstün \& Sartorius, 1995; Schnurr \& Green, 2004; North et al. 2009). For these reasons, Spitzer et al. (2009) argued that PTSD can mediate the effects of trauma on chronic respiratory disease. Third, chronic respiratory symptoms could serve as recurrent reminders of the horrors of a traumatic event and elevate PTSD rates (Yellowlees \& Kalucy, 1990); that is, pulmonary problems may mediate effects of trauma on PTSD.

The present study explores the associations of WTC exposures with probable PTSD, respiratory symptoms and lung function abnormality in rescue, recovery and clean-up workers participating in the WTC-MMTP. The cohort is composed of workers trained in disaster response (e.g. police; $n=8508$ ) and non-traditional responders in other occupations (e.g. building trades, maintenance, communications, transportation, health care, and other volunteers; $n=12333$ ). Previous research documented that professional responders to disasters report fewer mental health symptoms than volunteers with no previous disaster training (Perrin et al. 2007; Thormar et al. 2010). We thus stratified the cohort into police and non-traditional responders both to compare the rates of PTSD and respiratory symptoms and to examine the associations among these conditions. We explored three alternative hypotheses: (1) PTSD statistically mediated the association of exposure with pulmonary health; (2) respiratory problems mediated the association of exposure with PTSD; or (3) their co-morbidity was due to shared risk factors.

\section{Method}

\section{The sample}

Data come from patients evaluated at the WTCMMTP, which comprises seven clinics in New York and New Jersey. The program is available to WTC responders who $(a)$ had qualifying involvement in the WTC clean-up and recovery effort; and $(b)$ were not eligible to participate in other federally funded programs offered to the New York City Fire Department or to federal or state employees (Herbert et al. 2006). 
WTC responders were recruited to the program through an extensive outreach effort that included union meetings, mailings, media articles, and some 50000 telephone calls in multiple languages. The data for the current study were derived from the initial examinations that took place on average 4 years after 11 September 2001, between 16 July 2002 and 11 September 2008.

Institutional Review Boards of each affiliated site approved and monitored compliance with procedures for obtaining informed consent and protecting human subjects. More than $90 \%$ of clinic patients provided written informed consent for their data to be used for research purposes ( $n=22894$ participants). Complete data on all study variables were available for $n=$ 20 841. The excluded group was within two percentage points of the analysis sample on all study variables except working in law enforcement $(34.1 \%$ of excluded versus $40.8 \%$ of the analysis sample), long work on site $(22.4 \%$ v. $25.1 \%)$ and probable PTSD $(20.5 \%$ v. $16.0 \%)$.

\section{Measures}

WTC exposures

WTC exposure was assessed with two indices previously found to be significantly associated with both mental and physical health (e.g. Brackbill et al. 2006): dust cloud exposure (DiGrande et al. 2011), which occurred among responders who arrived on 11 September 2001 and worked on or near the debris pile; and long duration of work at Ground Zero, the Fresh Kills landfill (where debris from the disaster was brought), or the Office of the Chief Medical Examiner. The median duration of work was $633 \mathrm{~h}$ (interquartile range 191-1353 h). Long duration was defined as being in the top quartile ( $>1353 \mathrm{~h}$ ).

\section{Probable PTSD}

Probable WTC-related PTSD was measured using the PCL (Weathers et al. 1993), a 17-item self-report measure assessing the criterion symptoms listed in DSM-IV. Participants were asked to rate problems they were bothered by in the past month 'in relation to $9 / 11^{\prime}$ on a scale of ' $1=$ not at all' to ' $5=$ extremely'. The scale was summed, and a score of $\geqslant 50$ was used to indicate probable PTSD (Terhakopian et al. 2008). Item no. 5 asks about 'having physical reactions (e.g. heart pounding, trouble breathing, sweating) when something reminded you of the disaster'. To test whether this item influenced the association between PTSD and respiratory symptoms, we also scored PTSD by summing the other 16 items and applying a prorated cut-point of 47 .

\section{Lower respiratory symptoms}

Lower respiratory symptoms were rated by WTCMMTP physicians using questions selected from standard sources (Burney et al. 1989; National Center for Health Statistics, 1996; NIOSH, 2006). Seven lower respiratory symptoms were assessed: shortness of breath (under a variety of circumstances and times of day), wheezing, chest tightness, exercise intolerance, dry cough, hemoptysis, and productive cough. We focused on the development of one or more new symptoms after 11 September 2001 that persisted in the month before examination.

\section{Pulmonary function}

Pulmonary function was evaluated using the EasyOne $^{\mathrm{TM}}$ spirometer (ndd Medical Technologies, USA) following standard techniques (Miller et al. 2005; Enright et al. 2008). Consistent with previous reports on WTC responders (Herbert et al. 2006; Skloot et al. 2009), we focused on restrictive breathing pattern as measured by tests of forced vital capacity (FVC) and forced expiratory volume in one second (FEV1). Abnormal pulmonary function was based on the trial yielding the largest sum of FVC+FEV1 and defined as scoring below versus within/above the age-sex-race-height-specific lower limit of normal (Hankinson et al. 1999).

\section{Additional risk factors}

Other established risk factors, such as body mass index (BMI) and current tobacco use (e.g. Eaton, 2005; Von Korff et al. 2009), were adjusted in all multivariate analyses. Current age, sex and time (in years) from 9/11 to assessment were also adjusted when the bivariate analysis indicated that they were significantly related to the health variables.

\section{Analysis methods}

We first compared police and non-traditional responders on the study variables using $\chi^{2}$ tests for categorical data and $t$ tests for continuous variables. To evaluate bivariate associations among the variables, we used polychoric correlations when continuous variables were involved and tetrachoric correlations when both variables were dichotomous to produce equivalent estimates for continuous variables, dichotomous variables, and a mix of the two. Polychoric and tetrachoric correlations have a clear interpretation, with $r=0.10$ conventionally considered a small effect, $r=0.30$ a medium effect and $r=0.50$ a large effect (Cohen, 1988). 


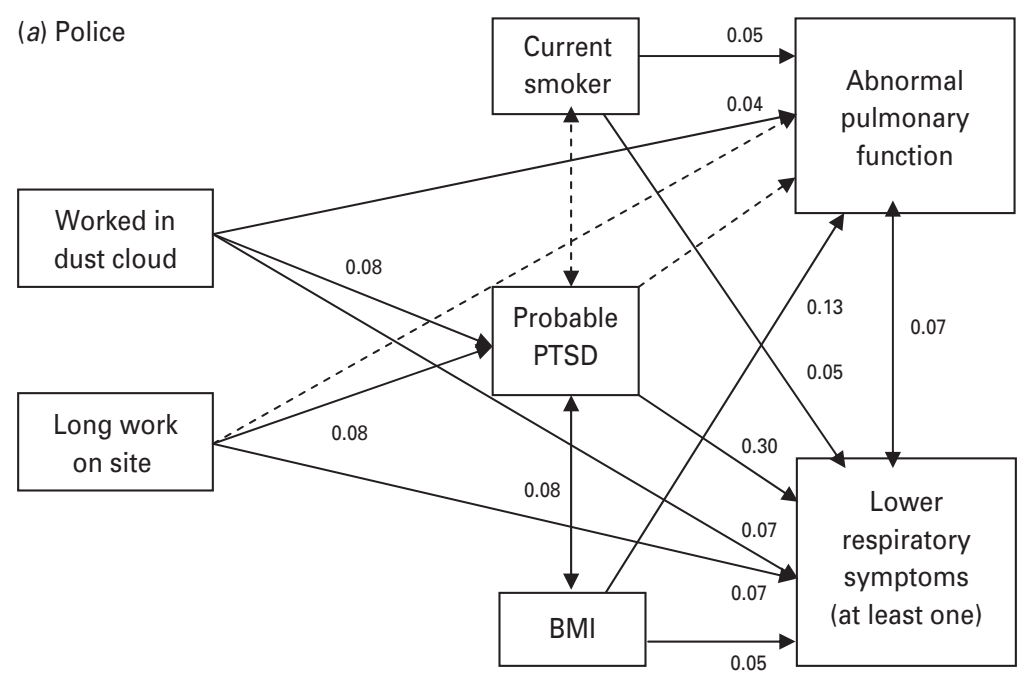

(b) Non-traditional responders

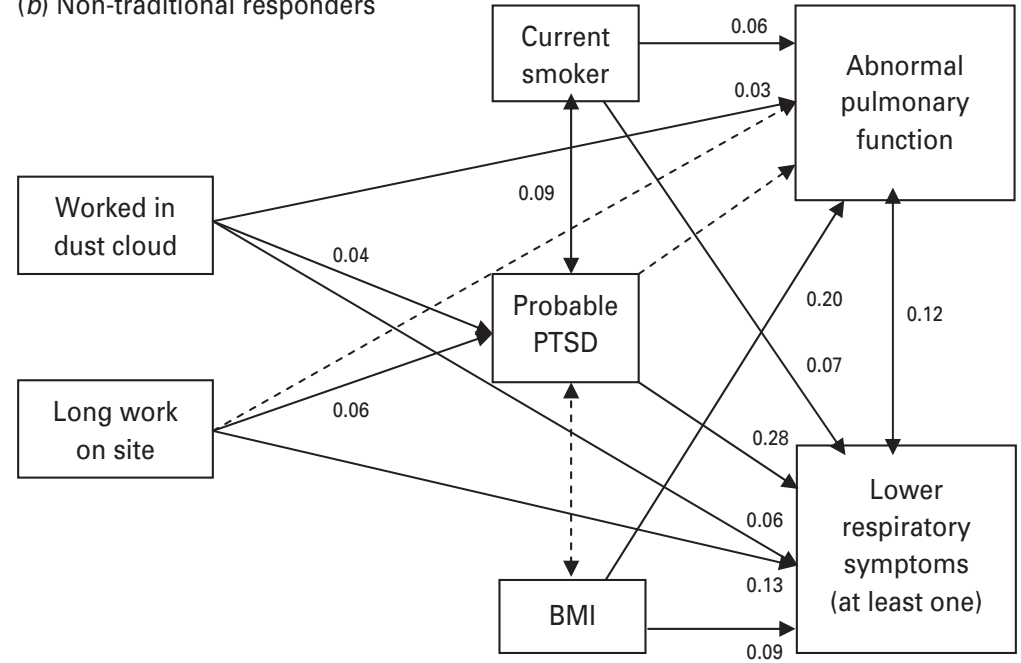

Fig. 1. Best-fitting structural equation models for $(a)$ police and $(b)$ non-traditional responders. Values are standardized path coefficients. Non-significant $(p>0.05)$ coefficients are not shown, and the corresponding paths are shown as broken lines. Correlations among covariates are not shown. Analyses adjusted for age, gender and time to assessment (not shown) whenever they were significantly correlated with the outcome (Table 2). Age, gender and time to assessment had paths to probable post-traumatic stress disorder (PTSD); age and gender had paths to pulmonary function; time to assessment had a path to lower respiratory symptoms. Directional arrows indicate regression paths; double-headed arrows indicate correlations. BMI, Body mass index.

Structural equation modeling (SEM), a system of multiple regressions that are estimated simultaneously (Kline, 2011), was used to explore the plausibility of the three alternative hypotheses about the pathways from exposure to PTSD and respiratory conditions. In the first model, WTC exposures were associated with PTSD and respiratory problems, and these conditions were correlated but independent. In the second model, associations between exposure and respiratory problems were statistically mediated in part by PTSD. Hence, in addition to direct paths, we included paths that went from exposures to PTSD and then from PTSD to respiratory problems
(Fig. 1). In the third model, associations between exposure and PTSD were mediated in part by respiratory conditions. In the latter two analyses, we tested the statistical significance of the indirect paths. In each model, we adjusted for smoking status and BMI in addition to the other risk factors that were significantly associated with the health outcome in the bivariate analyses. The analyses were performed using Mplus version 6.1 (Muthén \& Muthén, 2010). We used the maximum likelihood robust (MLR) estimator, which can handle non-normal distributions. In evaluating the model, we considered two absolute and three relative fit indices available in Mplus (Akaike, 1974; 
Table 1. Comparison of police and non-traditional responders on study variables ${ }^{\mathrm{a}}$

\begin{tabular}{llll}
\hline & $\begin{array}{l}\text { Police } \\
(n=8508)\end{array}$ & $\begin{array}{l}\text { Non-traditional } \\
\text { responders }(n=12333)\end{array}$ & $p$ value \\
\hline Years from 9/11 to assessment, mean (s.D.) & $4.1(1.8)$ & $3.4(1.9)$ & $<0.001$ \\
Current age (years), mean (s.D.) & $40.8(6.6)$ & $44.4(9.9)$ & $<0.001$ \\
Sex: female, \% & 15.0 & 13.9 & $<0.05$ \\
Worked in dust cloud, \% & 28.9 & 12.7 & $<0.001$ \\
Long work on site, \% & 22.8 & 26.8 & $<0.001$ \\
BMI, mean (s.D.) & $30.0(4.9)$ & $29.3(5.3)$ & $<0.001$ \\
Current cigarette smoker, \% & 10.2 & 20.3 & $<0.001$ \\
Probable WTC-related PTSD, \% & 5.9 & 23.0 & $<0.001$ \\
Abnormal pulmonary function, \% & 23.7 & 22.1 & $<0.05$ \\
Lower respiratory symptoms, \% & 22.5 & 28.4 & $<0.001$ \\
\hline
\end{tabular}

BMI, Body mass index; WTC, World Trade Center; PTSD, post-traumatic stress disorder; s.D., standard deviation.

${ }^{a}$ Dichotomous variables were compared using the $\chi^{2}$ test. Continuous variables were compared using the $t$ test.

Kass \& Raftery, 1995; Burnham \& Anderson, 2002; Marsh et al. 2004).

\section{Results}

\section{Sample characteristics}

The police cohort differed significantly $(p<0.001)$ from the non-traditional responders on most study variables (Table 1). Police were less likely to have probable WTC-related PTSD (5.9\% v. 23.0\%) and to have respiratory symptoms $(22.5 \%$ v. $28.4 \%)$. However, the proportion with abnormal pulmonary function was similar $(\sim 23 \%)$. With regard to exposure, more than twice as many police $(28.9 \%)$ compared to nontraditional responders $(12.7 \%)$ were exposed to the dust cloud, but more non-traditional responders $(26.8 \%)$ than police $(22.8 \%)$ spent prolonged time working at the site. In addition, most of the police $(n=7898 ; 92.8 \%)$ and non-traditional responders $(\mathrm{n}=10489 ; \quad 85.0 \%)$ reported working during September, 2001. Among them, $40.0 \%$ of police and $33.1 \%$ of non-traditional responders reported spending the majority of their time on or in the debris pile or pit; a further $42.5 \%$ of police and $58.9 \%$ of nontraditional responders worked in adjacent areas. The remainder were at the landfill, medical examiner's office, loading piers, and elsewhere.

With respect to background characteristics, police officers were younger, had slightly higher BMI, were less likely to smoke cigarettes, and were examined somewhat later than non-traditional responders.

\section{Bivariate associations}

Table 2 shows the bivariate associations among the study variables. Overall, the associations among the health variables were similar in the two groups.
Abnormal lung function was only modestly correlated with respiratory symptoms $(r=0.09$ in police and 0.13 in the non-traditional group) and was not significantly associated with probable PTSD. By contrast, lower respiratory symptoms were substantially associated with probable PTSD ( $r=0.28$ and 0.27 respectively). The associations were the same to the second decimal when we substituted the revised PTSD variable that excluded PCL item no. 5.

WTC exposures showed notable associations with lower respiratory symptoms (range $r=0.14-0.24$ ), less so with probable PTSD $(r=0.07-0.12)$, and were only weakly associated with lung function. Indeed, for PTSD and respiratory symptoms, the odds ratios (ORs) among police ranged from 1.4 [95\% confidence interval (CI) 1.2-1.8] for dust cloud exposure with probable PTSD to 1.6 for dust cloud exposure and long hours worked with respiratory symptoms (95\% CI 1.5-1.8 and 1.4-1.8 respectively). Among nontraditional responders, the ORs ranged from 1.2 for both dust cloud exposure and long hours worked with probable PTSD (95\% CI 1.1-1.4 for each) to 2.0 (95\% CI 1.8-2.2) for long hours worked with respiratory symptoms.

Among the other risk factors, higher BMI was significantly associated with pulmonary abnormality, and smoking was most strongly associated with respiratory symptoms. The other risk factors were significantly associated with at least one health variable and hence were adjusted in the multivariate models.

\section{Path models}

Each of the three models examined with SEM fit the data well (Supplementary Table S1, available online). However, the model in which associations between exposures and respiratory problems were mediated 
Table 2. Correlations among study variables in police (below diagonal) and non-traditional responders (above diagonal)

\begin{tabular}{|c|c|c|c|c|c|c|c|c|c|c|}
\hline & $\begin{array}{l}\text { Time to } \\
\text { assess- } \\
\text { ment }\end{array}$ & Age & Female & $\begin{array}{l}\text { Worked } \\
\text { in dust } \\
\text { cloud }\end{array}$ & $\begin{array}{l}\text { Long } \\
\text { work } \\
\text { on site }\end{array}$ & BMI & $\begin{array}{l}\text { Current } \\
\text { smoker }\end{array}$ & $\begin{array}{l}\text { Probable } \\
\text { PTSD }\end{array}$ & $\begin{array}{l}\text { Pulmonary } \\
\text { function }\end{array}$ & $\begin{array}{l}\text { Lower } \\
\text { respiratory } \\
\text { symptoms }\end{array}$ \\
\hline Time to assessment & - & 0.14 & 0.04 & 0.00 & -0.14 & 0.06 & -0.05 & 0.08 & 0.04 & -0.22 \\
\hline Age & 0.17 & - & -0.03 & 0.04 & -0.05 & 0.06 & -0.14 & 0.02 & 0.13 & 0.00 \\
\hline Female & 0.06 & -0.01 & - & -0.08 & -0.06 & -0.18 & -0.16 & 0.19 & -0.15 & 0.01 \\
\hline Worked in dust cloud & -0.14 & 0.01 & -0.06 & - & 0.09 & 0.07 & -0.01 & 0.07 & 0.08 & 0.14 \\
\hline Long work on site & -0.06 & -0.01 & 0.03 & 0.18 & - & 0.03 & 0.11 & 0.07 & -0.02 & 0.24 \\
\hline BMI & 0.04 & 0.06 & -0.26 & 0.02 & 0.05 & - & -0.08 & -0.02 & 0.21 & 0.07 \\
\hline Current smoker & -0.08 & -0.04 & 0.13 & 0.00 & 0.00 & -0.15 & - & 0.12 & 0.07 & 0.15 \\
\hline Probable PTSD & 0.11 & 0.14 & 0.05 & 0.11 & 0.12 & 0.08 & 0.06 & - & 0.03 & 0.27 \\
\hline Pulmonary function & -0.02 & 0.02 & -0.22 & 0.06 & 0.01 & 0.15 & 0.05 & 0.03 & - & 0.13 \\
\hline $\begin{array}{l}\text { Lower respiratory } \\
\text { symptoms }\end{array}$ & -0.17 & 0.04 & 0.06 & 0.17 & 0.16 & 0.08 & 0.11 & 0.28 & 0.09 & - \\
\hline
\end{tabular}

BMI, Body mass index; PTSD, post-traumatic stress disorder.

Correlations involving continuous variables are polychoric; all others are tetrachoric. Correlations $>0.03$ are significant at $p<0.05$ level.

Noteworthy associations $(r \geqslant 0.15)$ are shown in bold.

in part by PTSD showed better absolute fit in both responder groups. The relative fit indices indicated that support for this pathway was much stronger (odds in favor of it were over 100:1) than for the alternatives. This model is presented in Fig. 1; significant paths are shown with solid lines, along with the coefficients, and non-significant paths are given with dashed lines, without coefficients. Time to assessment, age and sex were adjusted in these models whenever these variables were significantly correlated with the outcome (paths not shown). The results were similar for the two occupational groups except that, in police, BMI but not smoking was associated with probable PTSD, whereas among the non-traditional responders, smoking but not BMI was associated with PTSD. Overall, both WTC exposures were associated modestly but significantly with probable PTSD (range $\beta=0.04-0.08$ ), which in turn was substantially associated with respiratory symptoms $(\beta=0.28$ and 0.30$)$. Independent of this pathway, WTC exposures contributed directly to respiratory symptoms $(\beta=0.06-0.13)$, and smoking and BMI also showed weak but significant associations. We tested the indirect contributions of each WTC exposure to lower respiratory symptoms and found all of them to be significant $(p<0.002)$, indicating that these associations were partially mediated by PTSD. With regard to lung function, the exposures were weakly associated in both groups, and none of the indirect associations was significant, indicating that the links of exposures to lung function abnormality were independent of PTSD.

\section{Discussion}

Consistent with prior studies of WTC responder cohorts, abnormal pulmonary function, lower respiratory symptoms, and probable WTC-related PTSD were common an average of 4 years after the disaster. Specifically, nearly one-quarter of police and one-third of non-traditional responders had lower respiratory symptoms that emerged after $9 / 11$ and were present in the month prior to examination, and $22-24 \%$ had abnormal lung function findings. As expected, the prevalence of probable WTC-related PTSD in nontraditional responders without emergency response training $(23.0 \%)$ was considerably higher than among police responders (5.9\%). Consistent with prior studies (e.g. Perrin et al. 2007; Brackbill et al. 2009), dust cloud exposure and greater number of hours worked were associated with PTSD, and there was a significant association between probable PTSD and respiratory symptoms. Most importantly, our results suggested an indirect association of exposure with respiratory problems through PTSD, a finding that mirrors research conducted with Vietnam veterans (Schnurr \& Jankowski, 1999). Moreover, the associations observed in the final model were similar in both police and non-traditional responders. Thus, the current results both extend our understanding of the health of WTC-MMTP responders and add to a growing body of data on the link between PTSD and respiratory problems.

This study cannot determine whether PTSD mediates the direct effects of WTC exposures on 
respiratory symptoms or if it serves to mediate the chronicity, rather than the onset, of respiratory symptoms. Longitudinal data and a rigorous diagnosis of PTSD are needed to disentangle these possibilities. Future studies should also include direct measures to test possible biological (e.g. immunologic dysregulation) and cognitive (e.g. increased attention to somatic symptoms) mechanisms underlying the observed link.

There are other limitations that should be noted when drawing inferences from the results. The current sample is composed of volunteers, and prevalence estimates from this and responder cohorts in previous reports must be treated with caution (Savitz et al. 2008). It is also possible that PTSD increased the participation of individuals with respiratory symptoms and WTC exposures. Longitudinal research using data from subsequent visits will determine whether PTSD increased retention of individuals with these symptoms and exposures, but we have no way of assessing this bias with data from the initial visit. To enhance reliability, we focused on incident respiratory symptoms that appeared after $9 / 11$ rather than symptoms that started before $9 / 11$. Thus the rates reported here are lower than those in studies combining incident and prevalent cases (e.g. Farfel et al. 2008). We also limited the analysis to two reasonably independent exposures based on prior WTC findings. Future research should also consider other specific exposures. With regard to probable PTSD, the analysis sample had a somewhat lower rate than the excluded sample. Thus the prevalence estimates are conservative. As noted elsewhere, police officers may have underreported PTSD symptoms because of concerns about retaining their employment. Despite these limitations, our results clearly confirm that respiratory and PTSD conditions were common and co-morbid, and suggest that PTSD may be mediating the exposure-respiratory symptom relationship in both professional and nontraditional WTC responders.

Shortly after 9/11, WTC rescue and recovery workers began to report a variety of symptoms involving the lower respiratory system, including dyspnea, chest discomfort, and chronic cough. These reports were first noted among New York City Fire Department workers who developed cough and bronchial hyperactivity (WTC cough; Prezant et al. 2002). These findings were predominantly attributable to airway abnormalities. Intense exposure and early development of bronchial hyperactivity predicted persistence of reactive airway dysfunction 6 months later. Physiologically, there was a bronchodilator response and hyper-reactivity; radiographically, there was air trapping and thickening of the bronchial wall without evidence of parenchymal changes (Izbicki et al. 2007;
Prezant, 2008). However, the protean nature of the respiratory symptoms and the lack of physical or physiologic correlates of disease in some patients raised the possibility that the symptoms resulted from multiple etiologies. This notion received support in the present study, as we found that lower respiratory symptoms had a weak association with pulmonary function, and, consistent with Niles et al. (2011), their associations with probable PTSD were much stronger.

We initially expected that responders with intense and extensive exposure would display more severe pulmonary illness and higher levels of PTSD symptoms. We were therefore surprised not to find a correlation between abnormal spirometry results and PTSD. However, a one-time spirometry assessment is known to have low sensitivity and specificity for episodic respiratory illnesses. The link between respiratory symptoms and PTSD, although well documented in general, clinical and veteran populations, is not well understood. Further studies are needed to elucidate the precise biological and psychological mechanisms involved in populations with different exposure experiences. The stratification of our analysis by occupational status revealed that the police and the non-traditional responders differed with respect to WTC exposures and prevalence of probable PTSD. The latter may be explained by the characteristics of police officers, including the selection, training, previous exposure to traumatic events, 9/11 exposure differences and reporting biases, in addition to the availability of social support and mental health services during and after the disaster. Although PTSD was less common in police than non-police, the link between probable PTSD and lower respiratory symptoms (and the absence of an association with abnormal spirometry results) was similar in the two groups.

The results have important implications for understanding illness burden on responders following large-scale disasters. Respiratory illness, in particular, is multi-faceted and can be attributed to structural abnormalities, functional syndromes and somatization. The presence of probable PTSD may provide an important signal for clinicians regarding the etiology or persistence of such symptoms presented by the responders. As shown here, there is a substantial association between PTSD and respiratory symptoms. Regardless of which came first, PTSD or respiratory symptoms, our findings emphasize that mental health screening is as essential as screening for respiratory symptoms. Of course, a clinical diagnosis of PTSD and objective testing for physical conditions provide the most crucial evidence about co-morbidity, and longitudinal data are needed to validate the mediation results. Nonetheless, the current findings support 
treatment strategies that integrate physical and mental health targets (Von Korff et al. 1997).

The current results also support previous findings that the health and mental health effects of the WTC disaster are enduring (Wisnivesky et al. 2011). Understanding why some responders are at higher or lower risk for developing persistent health problems following a large-scale disaster is important for designing disaster preparedness and long-term treatment programs for health problems that may develop into more chronic conditions. The health consequences of disaster recovery and clean-up could be improved by a better understanding of the prior training and experiences of the responders who altruistically assist under the worst possible conditions and by providing non-traditional responders with some level of preparation before they go on site. A qualitative study by Johnson et al. (2005) found that non-traditional WTC responders felt ill-prepared for the recovery and cleanup work. Specifically, they felt overwhelmed by the clean-up duties and did not feel that they had proper protective equipment. In our study, this group reported significantly higher rates of probable PTSD than police. This finding suggests that better preventive interventions must be put in place for nontraditional responders who volunteer to participate in disaster-related activities (Reissman \& Howard, 2008). Providing psychological first-aid soon after the exposure is recommended to protect against the development of chronic stress-related disorders (Ursano et al. 2007).

In our age, the number of toxic events in which relatively large populations are exposed to concomitant physical and psychological traumas has increased dramatically. In the sample of WTC responders who participated in this study, there was a striking correlation between PTSD and respiratory symptoms, with evidence that PTSD might play a mediating role in the exposure-symptom relationship. The associations reported in this paper have set the stage for further research to elucidate the pathways for the development and maintenance of respiratory problems using a longitudinal design, a diagnostic measure of PTSD, and additional risk and protective factors. Scott et al. (2009) demonstrated that mental-physical comorbidity has both additive and synergistic effects on disability, underscoring the importance of disentangling the association of PTSD and respiratory symptoms in addition to the provision of integrated general medical and psychiatric care for disaster responders.

\section{Acknowledgments}

We are extremely grateful to the WTC rescue and recovery workers, who gave of themselves so readily in response to the WTC attacks and agreed to participate in this ongoing research effort. We also thank the clinical staff of the WTC-MMTP for their dedication and the labor and community organizations for their continued support. This work was supported by the Centers for Disease Control and Prevention (CDC) and the National Institute for Occupational Safety and Health (NIOSH), contract 200-2002-0038 and grants 5U1O 0H008232, U10 OH008225, U10 OH008216, U10 OH008223, U10 OH008239, and U10 OH008275. The findings and conclusions in this article are those of the authors and do not necessarily represent the official position of the NIOSH, the CDC, or the U.S. Public Health Service.

\section{Note}

Supplementary material accompanies this paper on the Journal's website (http:/ /journals.cambridge.org/ psm).

\section{Declaration of Interest}

None.

\section{References}

Akaike H (1974). A new look at the statistical model identification. IEEE Transactions on Automatic Control 19, 716-723.

Aldrich TK, Gustave J, Hall CB, Cohen HW, Webber MP, Zeig-Owens R, Cosenza K, Christodoulou V, Glass L, Al-Othman F, Weiden MD, Kelly KJ, Prezant DJ (2010). Lung function in rescue workers at the World Trade Center after 7 years. New England Journal of Medicine 362, 1263-1272.

Berninger A, Webber MP, Cohen HW, Gustave J, Lee R, Niles JK, Chiu S, Zeig-Owens R, Soo J, Kelly K, Prezant DJ (2010). Trends of elevated PTSD risk in firefighters exposed to the World Trade Center disaster: 2001-2005. Public Health Reports 125, 556-566.

Bills CB, Levy NA, Sharma V, Charney DS, Herbert R, Moline J, Katz CL (2008). Mental health of workers and volunteers responding to events of $9 / 11$ : review of the literature. Mount Sinai Journal of Medicine 75, 115-127.

Blechert J, Michael T, Grossman P, Lajtman M, Wilhelm FH (2007). Autonomic and respiratory characteristics of posttraumatic stress disorder and panic disorder. Psychosomatic Medicine 69, 935-943.

Boscarino JA, Chang J (1999). Electrocardiogram abnormalities among men with stress-related psychiatric disorders: implications for coronary heart disease and clinical research. Annals of Behavioral Medicine 21, 227-234.

Brackbill RM, Hadler JL, DiGrande L, Ekenga CC, Farfel MR, Friedman S, Perlman SE, Stellman SD, Walker DJ, Wu D, Yu S, Thorpe LE (2009). Asthma and posttraumatic stress symptoms $5-6$ years following 
exposure to the WTC terrorist attack. Journal of the American Medical Association 302, 502-516.

Brackbill RM, Thorpe LE, DiGrande L, Perrin M, Sapp 2nd JH, Wu D, Campolucci S, Walker DJ, Cone J, Pulliam P, Thalji L, Farfel MR, Thomas P (2006). Surveillance for World Trade Center disaster health effects among survivors of collapsed and damaged buildings. Morbidity and Mortality Weekly Report: Surveillance Summaries 55, 1-18.

Burney PG, Laitinen LA, Perdrizet S, Huckauf $H$, Tattersfield AE, Chinn S, Poisson N, Heeren A, Britton JR, Jones T (1989). Validity and repeatability of the IUATLD (1984) Bronchial Symptoms Questionnaire: an international comparison. European Respiratory Journal 2, 940-945.

Burnham KP, Anderson DR (2002). Model Selection and Multimodel Inference: A Practical Information-Theoretic Approach, 2nd edn. Springer-Verlag: New York, NY. CDC (2004). Mental health status of World Trade Center rescue and recovery workers and volunteers - New York City, July 2002-August 2004. Morbidity and Mortality Weekly Report. Surveillance Summaries 53, 812-815.

Chrousos GP (1995). The hypothalamic-pituitary-adrenal axis and immune-mediated inflammation. New England Journal of Medicine 332, 1351-1362.

Cohen J (1988). Statistical Power Analysis for the Behavioral Sciences, 2nd edn. Lawrence Erlbaum: Hillsdale, NJ.

Dales RE, Spitzer WO, Schechter MT, Suissa S (1989). The influence of psychological status on respiratory symptom reporting. American Review of Respiratory Disease 139, 1459-1463.

Delahanty DL, Dougall AL, Craig KJ, Jenkins FJ, Baum A (1997). Chronic stress and natural killer cell activity after exposure to traumatic death. Psychosomatic Medicine 59, 467-476.

DiGrande L, Neria Y, Brackbill RM, Pulliam P, Galea S (2011). Long-term posttraumatic stress symptoms among 3,271 civilian survivors of the September 11, 2001, terrorist attacks on the World Trade Center. American Journal of Epidemiology 173, 271-281.

Eaton WW (ed.) (2005). Medical and Psychiatric Comorbidity over the Course of Life. American Psychiatric Publishing: Arlington, VA.

Engel CC (2004). Somatization and multiple idiopathic physical symptoms: relationship to traumatic events and posttraumatic stress disorder. In Trauma and Health: Physical Health Consequences of Exposure to Extreme Stress (ed. P. P. Schnurr and B. L. Green), pp. 191-215. American Psychological Association: Washington, DC.

Enright P, Skloot G, Herbert R (2008). Standardization of spirometry in assessment of responders following manmade disasters: World Trade Center worker and volunteer medical screening program. Mount Sinai Journal of Medicine 75, 109-114.

Farfel M, DiGrande L, Brackbill R, Prann A, Cone J, Friedman S, Walker DJ, Pezeshki G, Thomas P, Galea S, Williamson D, Frieden TR, Thorpe L (2008). An overview of 9/11 experiences and respiratory and mental health conditions among World Trade Center Health Registry enrollees. Journal of Urban Health: Bulletin of the New York Academy of Medicine 85, 880-909.

Gavett SH (2003). World Trade Center fine particulate matter - chemistry and toxic respiratory effects: an overview. Environmental Health Perspectives 111, 971.

Goodwin RD, Jacobi F, Thefeld W (2003). Mental disorders and asthma in the community. Archives of General Psychiatry 60, 1125-1130.

Hankinson JL, Odencrantz JR, Fedan KB (1999). Spirometric reference values from a sample of the general U.S. population. American Journal of Respiratory and Critical Care Medicine 159, 179-187.

Herbert R, Moline J, Skloot G, Metzger K, Baron S, Luft B, Markowitz S, Udasin I, Harrison D, Stein D, Todd A, Enright P, Stellman JM, Landrigan PJ, Levin SM (2006). The World Trade Center disaster and the health of workers: five-year assessment of a unique medical screening program. Environmental Health Perspectives 114, 1853-1858.

Herbstman JB, Frank R, Schwab M, Williams DL, Samet JM, Breysse PN, Geyh AS (2005). Respiratory effects of inhalation exposure among workers during the clean-up effort at the World Trade Center disaster site. Environmental Research 99, 85-92.

Hoge CW, Terhakopian A, Castro CA, Messer SC, Engel CC (2007). Association of posttraumatic stress disorder with somatic symptoms, health care visits, and absenteeism among Iraq war veterans. American Journal of Psychiatry 164, 150-153.

Ironson G, Wynings C, Schneiderman N, Baum A, Rodriguez M, Greenwood D, Benight C, Antoni M, LaPerriere A, Huang HS, Klimas N, Fletcher MA (1997). Posttraumatic stress symptoms, intrusive thoughts, loss and immune function after Hurricane Andrew.

Psychosomatic Medicine 59, 128-141.

Izbicki G, Chavko R, Banauch GI, Weiden MD, Berger KI, Aldrich TK, Hall C, Kelly KJ, Prezant DJ (2007). World Trade Center 'sarcoid-like' granulomatous pulmonary disease in New York City Fire Department rescue workers. Chest 131, 1414-1423.

Johnson SB, Langlieb AM, Teret SP, Gross R, Schwab M, Massa J, Ashwell L, Geyh AS (2005). Rethinking first response: effects of the clean-up and recovery effort on workers at the World Trade Center disaster site. Journal of Occupational and Environmental Medicine 47, 386-391.

Kass RE, Raftery AE (1995). Bayes factors. Journal of the American Statistical Association 90, 773-795.

Kline RB (2011). Principles and Practice of Structural Equation Modeling, 3rd edn. Guilford Press: New York, NY.

Landrigan PJ, Lioy PJ, Thurston G, Berkowitz G, Chen LC, Chillrud SN, Gavett SH, Georgopoulos PG, Geyh AS, Levin S, Perera F, Rappaport SM, Small C; NIEHS World Trade Center Working Group (2004). Health and environmental consequences of the world trade center disaster. Environmental Health Perspectives 112, 731-739.

Levin S, Herbert R, Skloot G, Szeinuk J, Teirstein A, Fischler D, Milek D, Piligian G, Wilk-Rivard E, Moline J (2002). Health effects of World Trade Center site workers. American Journal of Industrial Medicine 42, 545-547. 
Lioy PJ, Georgopoulos P (2006). The anatomy of the exposures that occurred around the World Trade Center site: 9/11 and beyond. Annals of the New York Academy of Sciences 1076, 54-79.

Marsh HW, Hau KT, Wen Z (2004). In search of golden rules: comment on hypothesis-testing approaches to setting cutoff values for fit indexes and dangers in overgeneralizing $\mathrm{Hu}$ and Bentler's (1999) findings. Structural Equation Modeling 11, 320-341.

McEwen BS, Stellar E (1993). Stress and the individual. Mechanisms leading to disease. Archives of Internal Medicine 153, 2093-2101.

McGee JK, Chen LC, Cohen MD, Chee GR, Prophete CM, Haykal-Coates N, Wasson SJ, Conner TL, Costa DL, Gavett SH (2003). Chemical analysis of World Trade Center fine particulate matter for use in toxicologic assessment. Environmental Health Perspectives 111, 972-980.

Miller MR, Hankinson J, Brusasco V, Burgos F, Casaburi R, Coates A, Crapo R, Enright $P$, van der Grinten $C P$, Gustafsson P, Jensen R, Johnson DC, MacIntyre N, McKay R, Navajas D, Pedersen OF, Pellegrino R, Viegi G, Wanger J; ATS/ERS Task Force (2005). Standardisation of spirometry. European Respiratory Journal 26, 319-338.

Muthén LK, Muthén BO (2010). Mplus. Statistical Analyses with Latent Variables. User's Guide, 6th edn. Muthén \& Muthén: Los Angeles, CA.

National Center for Health Statistics (1996). NHANES III Reference Manuals and Reports [CD-ROM]. Centers for Disease Control and Prevention: Hyattsville, MD.

Niles JK, Webber MP, Gustave J, Cohen HW, Zeig-Owens R, Kelly KJ, Glass L, Prezant DJ (2011). Comorbid trends in World Trade Center cough syndrome and probable PTSD in firefighters. Chest. Published online: 5 May 2011. doi:10.1378/chest.10-2066.

NIOSH (2006). Health Hazard Evaluations. National Institute for Occupational Safety and Health (www.cdc.gov/niosh/ hhe/HHEprogram.html). Accessed 30 July 2011.

North CS, Pfefferbaum B, Vythilingam M, Martin GJ, Schorr JK, Boudreaux AS, Spitznagel EL, Hong BA (2009). Exposure to bioterrorism and mental health response among staff on Capitol Hill. Biosecurity and Bioterrorism 7, 379-388.

Perrin MA, DiGrande L, Wheeler K, Thorpe L, Farfel M, Brackbill R (2007). Differences in PTSD prevalence and associated risk factors among World Trade Center disaster rescue and recovery workers. American Journal of Psychiatry 164, 1385-1394.

Prezant DJ (2008). World Trade Center cough syndrome and its treatment. Lung 186 (Suppl. 1), S94-S102.

Prezant DJ, Weiden M, Banauch GI, McGuinness G, Rom WN, Aldrich TK, Kelly KJ (2002). Cough and bronchial responsiveness in firefighters at the World Trade Center site. New England Journal of Medicine 347, 806-815.

Reissman DB, Howard J (2008). Responder safety and health: preparing for future disasters. Mount Sinai Journal of Medicine 75, 135-141.

Savitz DA, Oxman RT, Metzger KB, Wallenstein S, Stein D, Moline JM, Herbert R (2008). Epidemiologic research on man-made disasters : strategies and implications of cohort definition for World Trade Center worker and volunteer surveillance program. Mount Sinai Journal of Medicine 75, 77-87.

Schnurr PP, Green BL (2004). Understanding relationships among trauma, post-traumatic stress disorder, and health outcomes. Advances in Mind-Body Medicine 20, 18-29.

Schnurr PP, Jankowski MK (1999). Physical health and posttraumatic stress disorder: review and synthesis. Seminars in Clinical Neuropsychiatry 4, 295-304.

Scott KM, Von Korff M, Alonso J, Angermeyer MC, Bromet E, Fayyad J, de Girolamo G, Demyttenaere K, Gasquet I, Gureje O, Haro JM, He Y, Kessler RC, Levinson D, Medina Mora ME, Oakley Browne M, Ormel J, Posada-Villa J, Watanabe M, Williams D (2009). Mental-physical co-morbidity and its relationship with disability: results from the World Mental Health Surveys. Psychological Medicine 39, 33-43.

Skloot GS, Schechter CB, Herbert R, Moline JM, Levin SM, Crowley LE, Luft BJ, Udasin IG, Enright PL (2009). Longitudinal assessment of spirometry in the World Trade Center Medical Monitoring Program. Chest 135, 492-498.

Spitzer C, Barnow S, Volzke H, John U, Freyberger H, Grabe HJ (2009). Trauma, posttraumatic stress disorder, and physical illness: findings from the general population. Psychosomatic Medicine 71, 1012-1017.

Stellman JM, Smith RO, Katz CL, Sharma V, Charney DS, Herbert R, Moline J, Luft BJ, Markowitz S, Udasin I, Harrison D, Baron S, Landrigan PJ, Levin SM, Southwick S (2008). Enduring mental health morbidity and social function impairment in World Trade Center rescue, recovery, and cleanup workers: the psychological dimension of an environmental health disaster. Environmental Health Perspectives 116, 1248-1253.

Tapp LC, Baron S, Bernard B, Driscoll R, Mueller C, Wallingford K (2005). Physical and mental health symptoms among NYC transit workers seven and one-half months after the WTC attacks. American Journal of Industrial Medicine 47, 475-483.

Terhakopian A, Sinaii N, Engel CC, Schnurr PP, Hoge CW (2008). Estimating population prevalence of posttraumatic stress disorder: an example using the PTSD checklist. Journal of Traumatic Stress 21, 290-300.

Thormar SB, Gersons BP, Juen B, Marschang A, Djakababa MN, Olff M (2010). The mental health impact of volunteering in a disaster setting: a review. Journal of Nervous and Mental Disease 198, 529-538.

Ursano RJ, Fullerton CS, Benedek DM, Hamaoka DA (2007). Hurricane Katrina: disasters teach us and we must learn. Academic Psychiatry 31, 180-182.

Üstün TB, Sartorius N (1995). Mental Illness in General Health Care: An International Study. John Wiley \& Sons Ltd: Chichester, UK.

Von Korff M, Gruman J, Schaefer J, Curry SJ, Wagner EH (1997). Collaborative management of chronic illness: essential elements. Annals of Internal Medicine 127, 1097-1102.

Von Korff MR, Scott KM, Gureje O (eds) (2009). Global Perspectives on Mental-Physical Comorbidity in the WHO World Mental Health Surveys. Cambridge University Press: New York, NY. 
Weathers F, Litz B, Herman D, Huska J, Keane T (1993). The PTSD Checklist (PCL): reliability, validity, and diagnostic utility. Paper presented at the Annual Convention of the International Society for Traumatic Stress Studies, San Antonio, TX.

Weisberg RB, Bruce SE, Machan JT, Kessler RC, Culpepper L, Keller MB (2002). Nonpsychiatric illness among primary care patients with trauma histories and posttraumatic stress disorder. Psychiatric Services 53, 848-854.

Wheeler K, McKelvey W, Thorpe L, Perrin M, Cone J, Kass D, Farfel M, Thomas P, Brackbill R (2007). Asthma diagnosed after 11 September 2001 among rescue and recovery workers: findings from the World Trade Center
Health Registry. Environmental Health Perspectives 115, 1584-1590.

Wisnivesky JP, Teitelbaum SL, Todd AC, Boffetta P, Crane M, Crowley L, de la Hoz RE, Dellenbaugh C, Harrison D, Herbert R, Kim H, Jeon Y, Kaplan J, Katz C, Levin S, Luft B, Markowitz S, Moline JM, Ozbay F, Pietrzak RH, Shapiro M, Sharma V, Skloot G, Southwick S, Stevenson LA, Udasin I, Wallenstein S, Landrigan PJ (2011). Persistence of multiple illnesses in World Trade Center rescue and recovery workers : a cohort study. Lancet 378, 888-897.

Yellowlees PM, Kalucy RS (1990). Psychobiological aspects of asthma and the consequent research implications. Chest 97, 628-634. 